\title{
Ultrassonografia quantitativa do fígado de gatos hígidos - Nota prévia
}

\author{
Quantitative ultrasonography of the liver in healthy cats \\ Jessica Nascimento Moraes MONTEIRO ${ }^{1}$; Warley Gomes dos SANTOS $^{1}$; Daniel Capucho de \\ OLIVEIRA $^{1}$; Daniel Cometti BORLINI ${ }^{1}$; Sebastião MARTINS FILHO ${ }^{2}$; Flávia Mara MACHADO ${ }^{3}$; \\ Fabiano Séllos COSTA ${ }^{1}$ \\ ${ }^{1}$ Departamento de Medicina Veterinária da Universidade Federal do Espírito Santo, Alegre-ES \\ ${ }^{2}$ Departamento de Informática, Universidade Federal de Viçosa, Viçosa-MG \\ ${ }^{3}$ Centro Universitário Vila Velha, Vila Velha-ES
}

\begin{abstract}
Resumo
O exame ultrassonográfico apresenta divergência na interpretação dos seus achados, devido à análise subjetiva e individual. Avaliou-se ultrassonograficamente a quantificação dos níveis de cinza de fígado de 18 gatos hígidos pela técnica de histograma, obtendo-se medidas referentes à ecogenicidade (LMEAN), ecotextura (NMOST/NALL) e desvio padrão da amplitude do eco (SD). As médias e desvio padrão dos valores encontrados foram para LMEAN 5,6 $\pm 1,08$, NMOST/NALL 28,31 $\pm 3,84$ e SD 11,48 $\pm 1,77$. Ressalta-se a importância da técnica do histograma na padronização de valores de normalidade referentes à ecogenicidade e ecotextura do fígado, favorecendo o diagnóstico e o monitoramento de hepatopatias difusas.
\end{abstract}

Palavras-chave: Ultrassonografia. Histograma. Fígado. Gatos.

\begin{abstract}
The ultrasonographic exam presents divergence in the interpretation of its findings, due to subjective and individual analysis. The livers of 18 healthy cats were evaluated by the ultrasonographic exam, making use of the gray-level histograms method. There were taken measures referring to the echogenicity (LMEAN), echotexture (NMOST/NALL) and echo amplitude standard deviation (SD). The mean values and standard deviations observed in this clinical assay were: LMEAN $5.6 \pm 1.08$, NMOST/NALL $28.31 \pm 3.84$ e SD $11.48 \pm 1.77$. The gray-level histograms method is very important for the standardizing of hepatic echogenicity and echotexture values, helping in the diagnosis and monitoring of diffuse hepatopathies.
\end{abstract}

Keywords: Ultrasound. Histogram. Liver. Cats.

O exame ultrassonográfico do fígado possui inúmeros benefícios em pequenos animais, entretanto, pode apresentar divergência na interpretação dos seus achados devido à análise subjetiva e individual ${ }^{1,2,3,4}$. Diversos fatores influenciam no estabelecimento do diagnóstico ultrassonográfico, tais como a experiência do avaliador, aparelho utilizado, a frequência do transdutor, a regulagem de profundidade, ganho e contraste ${ }^{4,5}$. Adicionalmente, inúmeras enfermidades que acometem o fígado também podem promover alterações em órgãos padrões que são usados para comparação da ecogenicidade e textura do fígado, dificultando o diagnóstico ${ }^{4,6}$.
Ultrapassar a barreira da subjetividade é o objetivo da técnica quantitativa do histograma ${ }^{5,7,8,9,10}$. A análise de histograma está disponível em muitos aparelhos ultrassonográficos comerciais, entretanto sua aplicação tem sido restrita ao meio acadêmico, carecendo padronização de valores para maior uso na prática

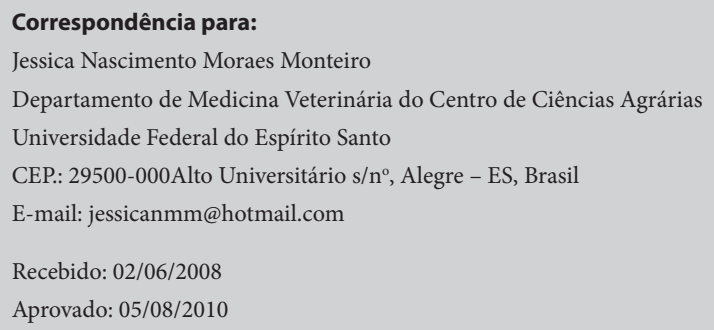


clínica ${ }^{5}$. Protocolos experimentais são descritos utilizando o método de histograma na medicina humana e veterinária ${ }^{5,6,7,8}$. O objetivo deste estudo é estabelecer valores quantitativos referentes à ecotextura e ecogenicidade do parênquima hepático de gatos hígidos pela técnica de histograma dos níveis de cinza.

Utilizaram-se para análise 18 gatos adulto-jovens, com o peso variando entre dois e quatro quilogramas, sem distinção de sexo ou raça. Foram selecionados animais normais ao exame clínico e com níveis séricos normais de fosfatase alcalina total, gama glutamiltransferase, aspartato aminotransferase, alanina aminotransferase, ureia e creatina. $\mathrm{O}$ aparelho ultrassonográfico empregado foi o modelo HS-2000 da Honda, sendo os animais avaliados, após tricotomia da região abdominal, com transdutor linear de $10,0 \mathrm{MHz}$ e ganho 71. As mensurações foram obtidas a partir da seleção de uma região quadrangular com área de $25 \mathrm{~mm}^{2}$, lateralmente à vesícula biliar e profundidade entre dois e três centímetros (Figura 1), sendo todos os exames realizados por um único observador.
Os valores descritos na tabela 1 são referentes às medidas quantitativas da região avaliada no parênquima hepático, sendo que os valores de LMEAN referem-se à ecogenicidade, demonstrando precisamente o grau de reflexão das ondas ultrassonográficas. $\mathrm{O}$ parâmetro NMOST/NALL indica a ecotextura da região avaliada e o SD indica o desvio padrão da amplitude do eco.

Conforme citado por Maeda, Utsu e Kihaile ${ }^{5}$, variações quanto à profundidade da região avaliada e o ganho utilizado durante o exame não influenciam estatisticamente nos resultados obtidos pela análise em histograma dos níveis de cinza. Os mesmos autores citam como pouco significativas as variações entre os aparelhos ultrassonográficos utilizados para o exame, entretanto, é recomendada a realização de novas pesquisas com outros modelos de equipamentos com o objetivo de se avaliar eventuais variações nos resultados.

A ultrassonografia quantitativa minimiza a necessidade de comparação do fígado com outras regiões, tais como ligamento falciforme, córtex renal e baço. Adicionalmente este método poderia auxiliar no diagnóstico de alterações hepáticas difusas e no monitora-

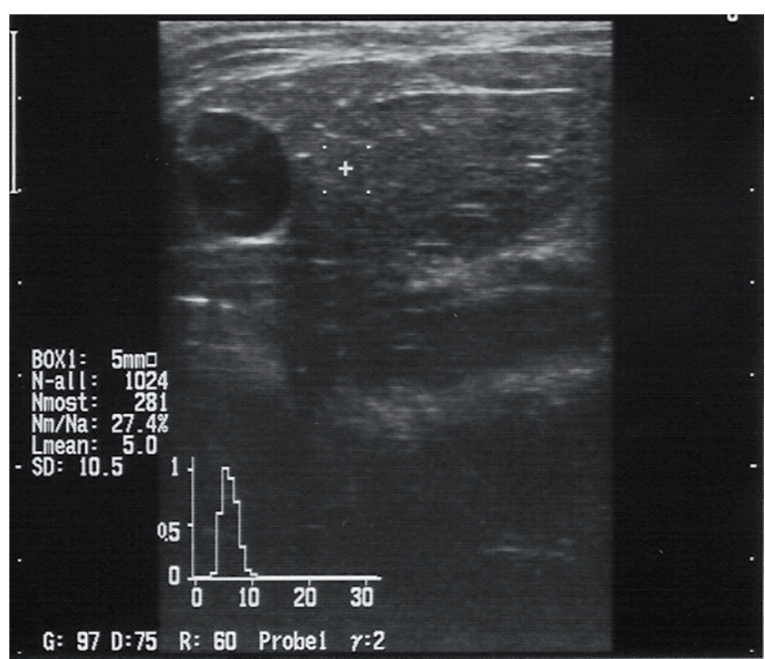

Figura 1 - Imagem ultrassonográfica do animal 14 demonstrando a avaliação quantitativa da ecotextura e ecogenicidade do fígado de gato hígido pela técnica de histograma em níveis de cinza. A seta aponta a área quadrangular referente a região analisada Alegre, ES - 2008 
Tabela 1 - Valores sonográficos das graduações de cinza parênquima hepático de gatos hígidos pela técnica do histograma, demonstrando valores individuais e medidas de tendência central das variáveis LMEAN, NMOST/NALL e SD de 18 gatos hígidos - Alegre, ES 2008

\begin{tabular}{|c|c|c|c|}
\hline ANIMAL & L MEAN* & NMOST/NALL ${ }^{* *}(\%)$ & $\mathrm{SD}^{\star * *}$ \\
\hline 1 & 5,6 & 25,3 & 11,4 \\
\hline 2 & 6,9 & 28,2 & 11,2 \\
\hline 3 & 5,5 & 31,0 & 11,2 \\
\hline 4 & 5,4 & 27,2 & 12,4 \\
\hline 5 & 4,6 & 29,5 & 12,6 \\
\hline 6 & 5,5 & 30,4 & 10,4 \\
\hline 7 & 5,8 & 22,6 & 14,8 \\
\hline 8 & 5,1 & 32,8 & 8,6 \\
\hline 9 & 4,8 & 28,3 & 9,9 \\
\hline 10 & 6,3 & 23,5 & 14,2 \\
\hline 11 & 3,7 & 33,0 & 10,5 \\
\hline 12 & 6,5 & 24,0 & 13,2 \\
\hline 13 & 6,5 & 22,9 & 13,8 \\
\hline 14 & 5,0 & 27,4 & 10,5 \\
\hline 15 & 3,1 & 37,2 & 8,4 \\
\hline 16 & 6,1 & 29,0 & 11,8 \\
\hline 17 & 6,6 & 29,5 & 10,5 \\
\hline 18 & 7,2 & 27,9 & 11,3 \\
\hline Médias & 5,6 & 28,31 & 11,48 \\
\hline Desvio-Padrão & 1,08 & 3,84 & 1,77 \\
\hline Variância & 1,16 & 14,76 & 3,14 \\
\hline
\end{tabular}

${ }^{*}$ LMEAN: medida quantitativa referente à ecogenicidade da região avaliada;

${ }_{* *}^{*}$ NMOST/NALL: medida quantitativa referente à ecotextura da região avaliada;

*** SD: desvio padrão da amplitude do eco.

mento de pacientes hepatopatas. A literatura cita uma dificuldade no diagnóstico acurado de algumas enfermidades difusas que afetam o fígado ${ }^{4,6} \mathrm{e}$ as medidas descritas neste trabalho podem então caracterizar-se como um coadjuvante nessas diferenciações.

Pode-se concluir que o método de histograma foi eficiente para determinar ecogenicidade e ecotextura do fígado de gatos saudáveis, possibilitando a caracterização de medidas de tendência central no grupo experimental. Ressalta-se que a aplicação desta técnica, quando avaliada conjuntamente com as demais características sonográficas, poderá facilitar o diagnóstico de hepatopatias em gatos.

\section{Referências}

1.NYLAND, T. G.; MATTOON, J. S.; HERRGESELL, E. J.; WISNER, E. R. Fígado. In: NYLAND, T. G.; MATTOON, J. S. Ultra-som diagnóstico em pequenos animais. 2. ed. São Paulo: Roca, 2004. p. 95-127.

2. MAMPRIM, M. J. Fígado e vesícula biliar. In: CARVALHO C. F. Ultra-sonografia em pequenos animais. São Paulo: Roca, 2004, p. 51- 73 .

3.PARTINGTON, B. P.; BILLER, D. S. Hepatic imaging with radiology and ultrasound. Veterinary Clinics of North America: Small Animal Practice, v. 25, n. 2, p. 305-335, 1995.

4.ZWEIBEL, W. J. Sonographic diagnosis of diffuse liver disease. Seminars in Ultrasound, CT, and MRI, v. 16, p. 8-15, 1995.

5.MAEDA, K.; UTSU, M.; KIHAILE, P. E. Quantification of sonographic echogenicity with grey-level histogram width: 
a clinical tissue characterization. Ultrasound in Medicine e Biology, v. 24, n. 2, p. 225-234, 1998.

6. KENNETH, J. W.; TAYLOR, M. D.; RIELY, C. A.; HAMMERS, L.; FLAX, S.; WELTIN, G.; GARCIA-TSAO, G.; CONN, H. O.; KUC, R.; BARWICK, K. W. Quantitative US attenuation in normal liver and in patients with diffuse liver disease: importance of fat. Radiology, v. 160, p. 65-71, 1986.

7.LU, Z. F.; ZAGZEBSKI, J. A.; O'BRIEN, R. T.; STEINBERG, $\mathrm{H}$. Ultrasound attenuation and backscatter in the liver during prednisone administration. Ultrasound in Medicine $\mathbf{e}$ Biology, v. 23, n. 1, p. 1-8, 1997.
8. OSAWA, H.; MORI, Y. Sonographic diagnosis of fatty liver using a histogram technique that compares liver and renal cortical echo amplitudes. Journal Clinical Ultrasound, v. 24, p. 25-29, 1996

9.LEE, H. C.; CHOI, J. W.; KIM, K. A.; SEO, T. S.; LEE, J. M.; PARK, C. M. Usefulness of standard deviation on the histogram of ultrasound as a quantitative value for hepatic parenchymal echo texture; preliminary study. Ultrasound in Medicine e Biology, v. 32, n. 12, p. 1817-1826, 2006.

10.NICOLL, R. G.; O'BRIEN; R. T.; JACKSON, M. W. Qualitative ultrasonography of the liver in obese cats. Veterinary Radiology Ultrasound, v. 39, n. 1, p. 47-50, 1998. 